\title{
Dose Determination for a Fixed-Dose Drug Combination: A Phase II Randomized Controlled Trial for Tiotropium/Olodaterol Versus Tiotropium in Patients with COPD
}

\author{
François Maltais • Alan Hamilton · Florian Voß • M. Reza Maleki-Yazdi
}

Received: October 26, 2018 / Published online: March 6, 2019

(C) The Author(s) 2019

\begin{abstract}
Introduction: During the clinical development of a fixed-dose combination of drugs, it is best practice to conduct dose-finding studies to determine the optimal dose of each component. The aims of this phase II dose-finding study were to confirm the lung function benefit of adding olodaterol to tiotropium, describe the dose-response relationship of olodaterol in combination with tiotropium $5 \mu \mathrm{g}$, and compare it with the dose response of olodaterol monotherapy.
\end{abstract}

Enhanced digital features To view enhanced digital features for this article go to https://doi.org/10.6084/ m9.figshare.7713635.

F. Maltais $(\bowtie)$

Research Center, Institut universitaire de cardiologie et de pneumologie de Québec, Université Laval, Québec City, Québec, Canada

e-mail: Francois.Maltais@fmed.ulaval.ca

A. Hamilton

Boehringer Ingelheim (Canada) Ltd., Burlington,

ON, Canada

F. Voß

Biostatistics and Data Sciences Corp., Boehringer Ingelheim Pharma GmbH \& Co. KG, Ingelheim Am Rhein, Germany

M. R. Maleki-Yazdi

Women's College Hospital, Division of Respiratory Medicine, University of Toronto, Toronto, ON, Canada
Methods: In this double-blind, parallel-group trial, patients were randomized to receive either tiotropium $5 \mu \mathrm{g}$ or a fixed-dose combination of tiotropium $5 \mu \mathrm{g}$ with olodaterol $2 \mu \mathrm{g}, 5 \mu \mathrm{g}$, or $10 \mu \mathrm{g}$, delivered once daily via the Respimat ${ }^{\circledR}$ for 4 weeks (NCT00696020). Patients had a diagnosis of chronic obstructive pulmonary disease and post-bronchodilator forced expiratory volume in $1 \mathrm{~s}\left(\mathrm{FEV}_{1}\right) \geq 30$ and $<80 \%$ of predicted normal. The primary endpoint was trough $\mathrm{FEV}_{1}$ response (change from baseline) after 4 weeks. Secondary endpoints included $\mathrm{FEV}_{1}$ and forced vital capacity (FVC) over $6 \mathrm{~h}$ after dosing.

Results: Compared with tiotropium $5 \mu \mathrm{g}$, mean (standard error) trough $\mathrm{FEV}_{1}$ increased with the addition of olodaterol $2 \mu \mathrm{g}$ by $0.024 \mathrm{~L}$ (0.027), olodaterol $5 \mu \mathrm{g}$ by $0.033 \mathrm{~L}(0.027)$, and olodaterol $10 \mu \mathrm{g}$ by $0.057 \mathrm{~L}$ (0.027). Statistically significant improvements in $\mathrm{FEV}_{1}$ versus tiotropium were seen across all timepoints up to $6 \mathrm{~h}$ with all doses of tiotropium/olodaterol. Similar results were observed for FVC.

Conclusion: There was a benefit of tiotropium/ olodaterol compared with tiotropium monotherapy in $\mathrm{FEV}_{1}$ and FVC. There was a dose-response relationship for olodaterol on top of tiotropium for $\mathrm{FEV}_{1}$ and $\mathrm{FVC}$ similar to the dose response previously seen for olodaterol monotherapy. These results, together with the results of a study investigating the dose response of tiotropium on top of olodaterol, 
helped to inform the dose selection for the phase III studies.

Funding: Boehringer Ingelheim International $\mathrm{GmbH}$.

Keywords: COPD; Dose-finding; Fixed-dose combination; Long-acting $\beta_{2}$-agonist; Longacting muscarinic antagonist; Respiratory/ pulmonary

\section{INTRODUCTION}

Tiotropium/olodaterol $5 / 5 \mu \mathrm{g}$, delivered via the Respimat ${ }^{\circledR}$, is an approved maintenance treatment for chronic obstructive pulmonary disease (COPD) that has been rigorously tested in a large clinical trial program [1-5]. Before the phase III program was started, phase II studies used a novel approach to establish the optimal doses to include in the combination. The doses of the two monotherapies had already been investigated $[6,7]$. When this study was designed, tiotropium Respimat $^{\circledR} 5 \mu \mathrm{g}$ was licensed in some, but not all, countries, with further evaluation of the $2.5 \mu \mathrm{g}$ and $5 \mu \mathrm{g}$ doses ongoing; meanwhile, olodaterol was still in development, with the phase III trials ongoing with $5 \mu \mathrm{g}$ and $10 \mu \mathrm{g}$. However, as there were some suggestions from the preclinical data that there may be a synergistic effect with tiotropium/olodaterol at subclinical doses [8], this study and two others investigated the optimal doses for the combination. The first, a phase II incomplete crossover trial (NCT01040403) investigated the dose response of tiotropium on top of olodaterol in a free-dose combination [9], whereas the other, a phase II crossover trial (NCT00720499) directly compared the fixeddose combinations tiotropium/olodaterol $5 / 5 \mu \mathrm{g}$ and $5 / 2 \mu \mathrm{g}$ (results available on clinicaltrials.gov) [10].

As de Miguel-Diez and Jimenez-Garcia point out, dose-finding studies are still required for combination products as the optimal doses are not necessarily the same as the monotherapies, and it is necessary to test for interactions between the two compounds [11].

The aims of this study were to confirm the lung function benefit of adding olodaterol to tiotropium and to describe the dose-response relationship of olodaterol when added to tiotropium. It was also intended to compare the dose-response relationship to that previously described of olodaterol monotherapy.

\section{METHODS}

This was a randomized, double-blind, parallel group, phase II trial conducted between June 2008 and February 2009 at 38 sites in Germany, Canada, and the USA. The trial was registered on clinicaltrials.gov (NCT00696020). Patients received either tiotropium $5 \mu \mathrm{g}$ or a fixed-dose combination of tiotropium/olodaterol $5 / 2 \mu \mathrm{g}$, $5 / 5 \mu \mathrm{g}$, or $5 / 10 \mu \mathrm{g}$ for 4 weeks, all delivered once daily via two puffs of the Respimat ${ }^{\circledR}$ inhaler. The olodaterol doses included were all used to investigate the dose response of olodaterol monotherapy [6]. Patients were randomized equally to the four treatment groups in blocks of four using a pseudo-random number generator. The sponsor arranged for the randomization, as well as the packaging and labelling of study medication. After screening, patients entered a 2-week run-in period prior to randomization. Following the 4 -week randomized treatment period, patients were evaluated for an additional 28 days.

Open-label salbutamol was provided as rescue medication, and patients were permitted to continue with inhaled corticosteroids throughout the trial if the dose they were receiving was stable for 6 weeks prior to screening.

Patients had a diagnosis of COPD, postbronchodilator forced expiratory volume in $1 \mathrm{~s}$ $\left(\mathrm{FEV}_{1}\right) \geq 30$ and $<80 \%$ of predicted normal, and post-bronchodilator $\mathrm{FEV}_{1} /$ forced vital capacity (FVC) $<70 \%$. They were at least 40 years of age, with a smoking history of greater than 10 pack-years. Exclusion criteria included significant disease other than COPD, history of asthma, or total blood eosinophil count $\geq 600 / \mathrm{mm}^{3}$, history of myocardial infarction within 1 year of screening or clinically relevant cardiac arrhythmia.

Pulmonary function tests were performed in the clinic prior to dosing and up to $3 \mathrm{~h}$ post- 
dose at baseline, week 1 , and week 2 , and prior to dosing and up to $6 \mathrm{~h}$ post-dose at week 4 .

The primary endpoint was trough $\mathrm{FEV}_{1}$ response (change from baseline) after 4 weeks of treatment. Trough $\mathrm{FEV}_{1}$ was defined as the mean of two $\mathrm{FEV}_{1}$ measurements taken at $1 \mathrm{~h}$ before and 10 min before the morning dose of medication. Secondary endpoints included trough $\mathrm{FEV}_{1}$ after 1 and 2 weeks of treatment; trough FVC after 1, 2, and 4 weeks of treatment; and peak $\mathrm{FEV}_{1(0-3 \mathrm{~h})}$ and $\mathrm{FVC}_{(0-3 \mathrm{~h})}$ responses after 4 weeks of treatment. Adverse events (AEs) and serious AEs (SAEs) were also monitored. An analysis of covariance (ANCOVA) model was used for the analysis of the primary and secondary endpoints. The primary endpoint was tested sequentially from highest dose to lowest dose, whereas all other endpoints were not adjusted for multiple testing and presented $p$ values are nominal.

On the basis of evidence available at the time, the standard deviation was predicted to be approximately $225 \mathrm{~mL}$, and the treatment difference versus tiotropium $5 \mu \mathrm{g}$ was predicted to be $120 \mathrm{~mL}$; this meant a sample size of 80 patients per treatment arm was selected for $90 \%$ power with a one-sided alpha equal to 0.025 .

\section{Compliance with Ethics Guidelines}

All procedures performed in studies involving human participants were in accordance with local ethics committees (coordinating investigator ethics board: Research Ethics Board, Institut universitaire de cardiologie et de pneumologie de Québec, Québec) and with the 1964 Declaration of Helsinki and its later amendments. Informed consent was obtained from all individual participants included in the study.

\section{RESULTS}

\section{Patient Disposition}

A total of 537 patients were enrolled in the trial, 360 of whom were randomized and treated (88-93 in each treatment group). In total, 13 patients discontinued prematurely (four with tiotropium $5 \mu \mathrm{g}$, two with tiotropium/olodaterol $5 / 2 \mu \mathrm{g}$, three with tiotropium/olodaterol $5 / 5 \mu \mathrm{g}$, and four with tiotropium/olodaterol $5 / 10 \mu \mathrm{g})$.

\section{FEV $_{1}$ and FVC}

\section{Primary Endpoint}

After 4 weeks, adjusted mean (standard error [SE]) trough $\mathrm{FEV}_{1}$ response was $0.110 \mathrm{~L}(0.021)$ with tiotropium $5 \mu \mathrm{g}(n=90)$. Compared with tiotropium $5 \mu \mathrm{g}$, mean trough $\mathrm{FEV}_{1}$ was increased with the addition of olodaterol $2 \mu \mathrm{g}$ by $0.024 \mathrm{~L}(0.027 ; n=89)$, olodaterol $5 \mu \mathrm{g}$ by $0.033 \mathrm{~L}(0.027 ; n=93)$, and olodaterol $10 \mu \mathrm{g}$ by $0.057 \mathrm{~L}(0.027 ; n=88)$. Only tiotropium/olodaterol $5 / 10 \mu \mathrm{g}$ reached statistical significance versus tiotropium $5 \mu \mathrm{g}(p=0.0337)$.

\section{Secondary Endpoints}

All doses of tiotropium/olodaterol resulted in significantly greater improvements in trough $\mathrm{FEV}_{1}$ compared with tiotropium $5 \mu \mathrm{g}$ after 1 week, and all except the lowest dose of tiotropium/olodaterol also showed significantly greater improvements in trough $\mathrm{FEV}_{1}$ compared with tiotropium $5 \mu \mathrm{g}$ after 2 weeks.

Peak FEV $_{1(0-3 \mathrm{~h})}$ response at week 4 was greater with all doses of tiotropium/olodaterol than with tiotropium $5 \mu \mathrm{g}$ (0.088 [SE 0.033], 0.082 [0.032], and $0.144 \mathrm{~L}$ [0.033] with $5 / 2 \mu \mathrm{g}$, $5 / 5 \mu \mathrm{g}$, and $5 / 10 \mu \mathrm{g}$ doses versus tiotropium, respectively; $p<0.05$ for all doses). At week 4 , $\mathrm{FEV}_{1}$ was significantly improved over time from drug administration to $6 \mathrm{~h}$ post-dose with all tiotropium/olodaterol doses versus tiotropium (Fig. 1).

Tiotropium/olodaterol $5 / 5 \mu \mathrm{g}$ and tiotropium/olodaterol $5 / 10 \mu \mathrm{g}$, but not tiotropium/olodaterol $5 / 2 \mu \mathrm{g}$, showed a significant effect on trough FVC compared with tiotropium $5 \mu \mathrm{g}$ after 1 week, 2 weeks, and 4 weeks $\left(p<0.05\right.$ for all doses). Peak $\mathrm{FVC}_{(0-3 \mathrm{~h})}$ response at week 4 was greater with all tiotropium/olodaterol doses than with tiotropium $5 \mu \mathrm{g}$ (treatment difference [SE] $0.131 \quad[0.060], 0.204$ [0.059], and $0.265 \mathrm{~L}$ [0.060] with $5 / 2 \mu \mathrm{g}, 5 / 5 \mu \mathrm{g}$, and $5 / 10 \mu \mathrm{g}$, respectively; $p<0.05$ for all doses). FVC at week 4 was significantly improved 


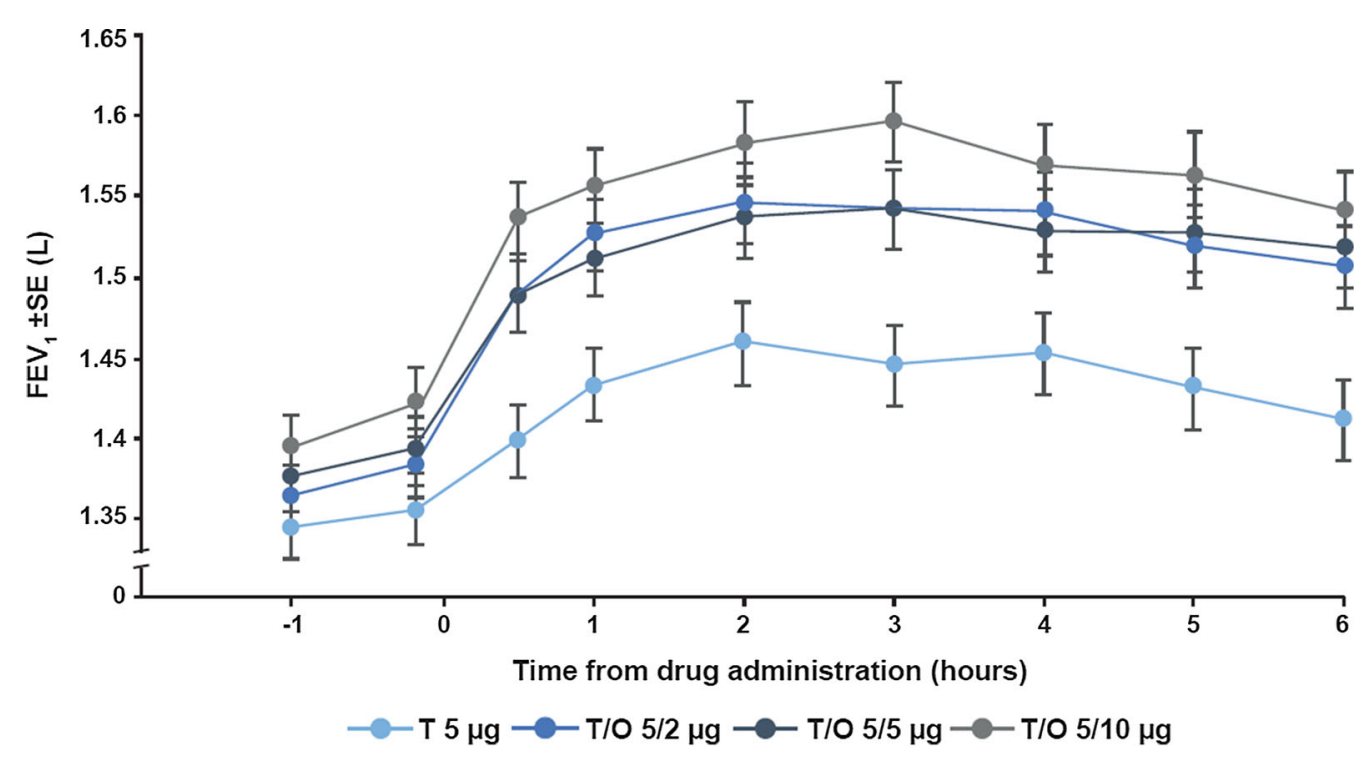

Fig. $1 \mathrm{FEV}_{1}$ over time at week $4 . \mathrm{FEV}_{1}$ forced expiratory volume in $1 \mathrm{~s}$, $\mathrm{O}$ olodaterol, SE standard error, $\mathrm{T}$ tiotropium

during the first $6 \mathrm{~h}$ from dosing with all tiotropium/olodaterol doses compared with tiotropium (Fig. 2).

\section{Safety}

A total of 117 patients (32.5\%) reported one or more AE (31 [34.4\%] with tiotropium $5 \mu \mathrm{g}$,
30 [33.7\%] with tiotropium/olodaterol $5 / 2 \mu \mathrm{g}$, 27 [29.0\%] with tiotropium/olodaterol $5 / 5 \mu \mathrm{g}$, and $29[33.0 \%]$ with tiotropium/olodaterol $5 / 10 \mu \mathrm{g})$. Most events were mild or moderate in intensity, and all SAEs were considered unrelated to study medication. There was no evidence of a dose relationship for any AE or SAE.

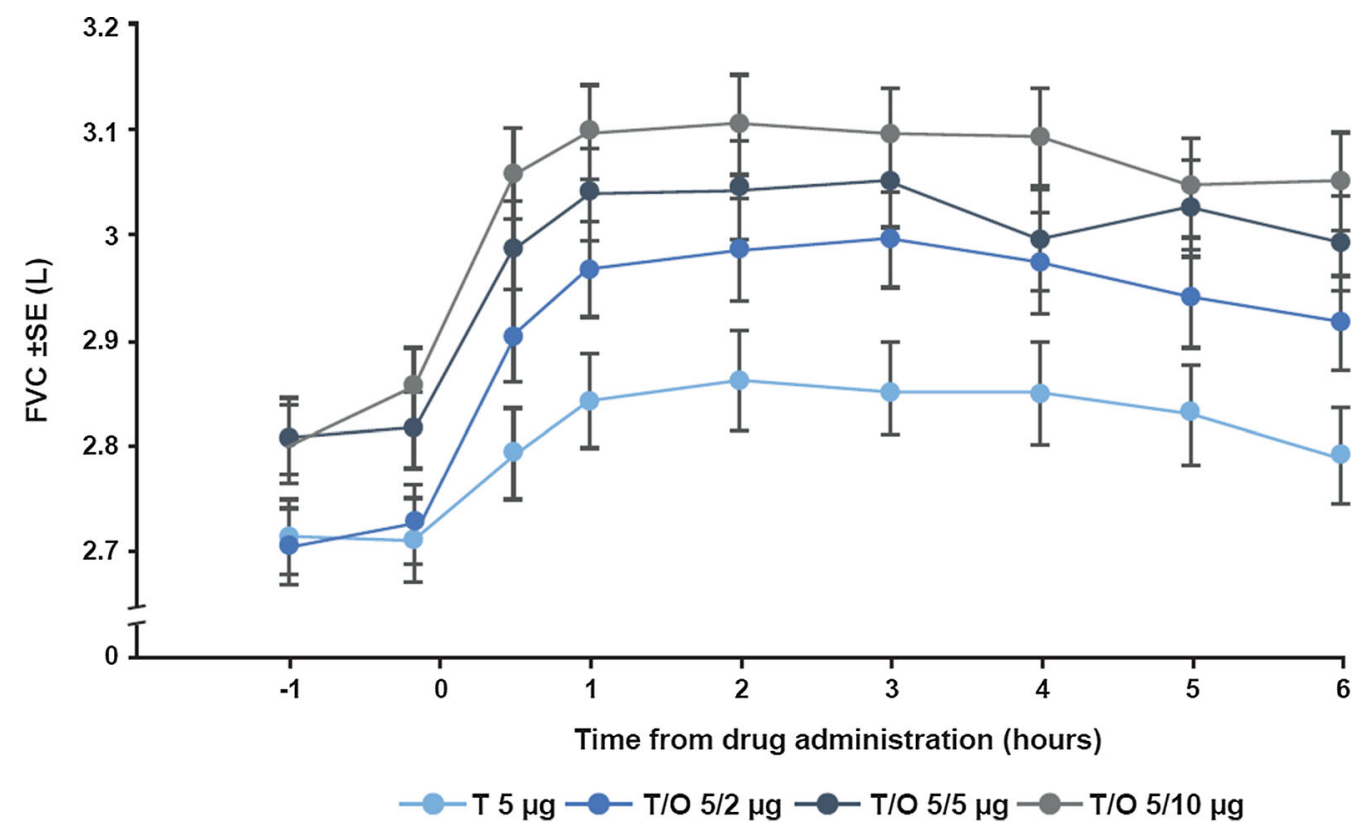

Fig. 2 FVC over time at week 4. FVC forced vital capacity, O olodaterol, SE standard error, T tiotropium 


\section{DISCUSSION}

These results show a dose-response relationship for olodaterol on top of tiotropium $5 \mu \mathrm{g}$ and that the combination was well tolerated. The increase in trough $\mathrm{FEV}_{1}$ after 4 weeks with olodaterol on top of tiotropium ranged from $0.024 \mathrm{~L}$ with the lowest dose $(2 \mu \mathrm{g})$ to $0.057 \mathrm{~L}$ with the highest dose $(10 \mu \mathrm{g})$, though only the $10 \mu \mathrm{g}$ dose reached statistical significance. There was a dose-response similar to that seen for olodaterol monotherapy. Tiotropium/olodaterol improved trough $\mathrm{FEV}_{1}, \mathrm{FEV}_{1}$ over time from drug administration up to $6 \mathrm{~h}$ post-dose, and FVC up to $6 \mathrm{~h}$ post-dose to a greater extent than did tiotropium monotherapy, although not all doses formally reached statistical significance according to the prespecified statistical testing strategy. In this study, however, achievement of statistical significance for the primary endpoint was not considered to be the only goal, as the aim was to ascertain whether there was a clear deviation from the previously described dose response for olodaterol monotherapy using all the evidence available.

The dose-response relationship observed in this study formed an important part of the rationale for the selection of the tiotropium/ olodaterol $2.5 / 5$ and $5 / 5 \mu \mathrm{g}$ doses for the phase III program. The dose response for olodaterol in combination with tiotropium $5 \mu \mathrm{g}$ observed in this study was similar to that of olodaterol monotherapy; importantly, the $2 \mu \mathrm{g}$ dose of olodaterol was on the steep part of the dose-response curve in both cases. In contrast, an additional 4-week phase II crossover study (1237.9) did not show any difference in efficacy $\left(\mathrm{FEV}_{1}\right)$ between olodaterol $2 \mu \mathrm{g}$ and olodaterol $5 \mu \mathrm{g}$ in fixed combination with tiotropium $5 \mu \mathrm{g}$. However, interpretation of these results was limited by the lack of additional fixed-dose combination treatment arms as well as the lack of a tiotropium monotherapy arm [10]. On the basis of these data, it was concluded that the dose response of olodaterol is not influenced by coadministration with tiotropium, so the dose selection for olodaterol monotherapy could be applied to the combination. The phase III clinical program for olodaterol monotherapy demonstrated similar efficacy for olodaterol $5 \mu \mathrm{g}$ and olodaterol $10 \mu \mathrm{g}[12,13]$. Therefore, $5 \mu \mathrm{g}$ was selected as the olodaterol dose within the combination product to be further evaluated in the tiotropium/olodaterol fixed-dose combination phase III program.

Tiotropium's dose response in combination with olodaterol was evaluated in trial 1237.18, a 4-week, incomplete crossover study in patients with moderate/severe COPD, which included tiotropium doses of $1.25 \mu \mathrm{g}, 2.5 \mu \mathrm{g}$, and $5 \mu \mathrm{g}$ in free combination (separate Respimat ${ }^{\circledR}$ inhalers) with olodaterol $5 \mu \mathrm{g}$ and olodaterol $10 \mu \mathrm{g}$ [9]. There was a stepwise, dose-ordered increase in lung function response for tiotropium $(1.25 \mu \mathrm{g}$, $2.5 \mu \mathrm{g}, 5 \mu \mathrm{g})$ in combination with both olodaterol $5 \mu \mathrm{g}$ and olodaterol $10 \mu \mathrm{g}$, similar to the dose response of tiotropium administered as monotherapy. This confirmed the rationale for selection of the tiotropium doses $2.5 \mu \mathrm{g}$ and $5 \mu \mathrm{g}$ used in the phase III studies of the fixeddose combination.

Given the results of the phase III program, which convincingly demonstrated efficacy of tiotropium/olodaterol $5 / 5 \mu \mathrm{g}$ on lung function (trough $\mathrm{FEV}_{1}$ ), exercise tolerance, and healthrelated quality of life (St George's Respiratory Questionnaire) [1-5], the results of the present study offer a cautionary note on sole reliance of statistical significance of a specific dose for phase III dose selection from phase II "therapeutic exploratory" studies; however, the dose-response curve should be considered. In this case, the dose that was eventually selected and licensed for use in COPD (tiotropium/olodaterol $5 / 5 \mu \mathrm{g}$ ) is the same as the monotherapy doses of each component. However, we investigated the dose response of both drugs in the combination in case there was a synergistic relationship or any pharmacodynamic interaction between the two drugs [11].

There are some limitations to this study. As it was a phase II dose-finding study, the number of patients in each arm is relatively small. The sample size was planned with a treatment difference of 115-120 mL, but the treatment effect was overestimated, resulting in a lack of power for the individual comparisons. Therefore, the study should be viewed as exploratory regarding the dose response of olodaterol on top of 
tiotropium, and the present results should be considered together with the results of the rest of the tiotropium/olodaterol fixed-dose combination phase II program.

\section{CONCLUSION}

There was a benefit of tiotropium/olodaterol compared with tiotropium monotherapy in $\mathrm{FEV}_{1}$ and FVC. There was a dose-response relationship for olodaterol on top of tiotropium for $\mathrm{FEV}_{1}$ and FVC similar to the dose response previously seen for olodaterol monotherapy. These results, together with the results of a study investigating the dose response of tiotropium on top of olodaterol, helped to inform the dose selection for the phase III studies.

\section{ACKNOWLEDGMENTS}

The authors would like to thank all the patients and their families for participating in this trial, and they also extend their thanks to the investigators.

Funding. Sponsorship for this study, article processing charges, and open access fee were funded by Boehringer Ingelheim International $\mathrm{GmbH}$. All authors had full access to all of the data in this study and take complete responsibility for the integrity of data and accuracy of the data analysis.

Medical Writing, Editorial, and other Assistance. Editorial assistance in the preparation of this article was provided by Claire Scofield of MediTech Media. Support for this assistance was funded by Boehringer Ingelheim Pharma GmbH \& Co. KG.

Authorship. All named authors meet the International Committee of Medical Journal Editors (ICMJE) criteria for authorship for this article, take responsibility for the integrity of work as a whole, and have given their approval for this version to be published.
Disclosures. François Maltais reports grants and personal fees from Boehringer Ingelheim, Novartis and AstraZeneca, and grants from GlaxoSmithKline and Grifols, outside of the submitted work. Alan Hamilton is an employee of Boehringer Ingelheim. Florian $\mathrm{Voß}$ is an employee of Boehringer Ingelheim. M. Reza Maleki-Yazdi acted as a consultant and has received research grants form Almirall, AstraZeneca, Boehringer Ingelheim, Forrest Laboratories, GlaxoSmithKline, Novartis, Merck, Ono Pharmaceuticals, and Pfizer.

Compliance with Ethics Guidelines. All procedures performed in studies involving human participants were in accordance with local ethics committees (coordinating investigator ethics board: Research Ethics Board, Institut universitaire de cardiologie et de pneumologie de Québec, Québec) and with the 1964 Declaration of Helsinki and its later amendments. Informed consent was obtained from all individual participants included in the study.

Data Availability. The datasets generated during and/or analyzed during the current study are available in Boehringer Ingelheim's Clinical Study Reports and Related Clinical Documents repository, https://trials. boehringer-ingelheim.com/trial_results/

clinical_submission_documents.html. All such requests will be governed by a Document Sharing Agreement. Bona fide, qualified scientific and medical researchers may request access to de-identified, analysable participant clinical study data with corresponding documentation describing the structure and content of the datasets. Upon approval, and governed by a Data Sharing Agreement, data are shared in a secured data-access system for a limited period of 1 year, which may be extended upon request. Researchers should use https:// clinicalstudydatarequest.com to request access to study data.

Open Access. This article is distributed under the terms of the Creative Commons Attribution-NonCommercial 4.0 International License (http://creativecommons.org/licenses/ by-nc/4.0/), which permits any noncommercial 
use, distribution, and reproduction in any medium, provided you give appropriate credit to the original author(s) and the source, provide a link to the Creative Commons license, and indicate if changes were made.

\section{REFERENCES}

1. Buhl R, Maltais F, Abrahams R, et al. Tiotropium and olodaterol fixed-dose combination versus mono-components in COPD (GOLD 2-4). Eur Respir J. 2015;45(4):969-79.

2. Beeh KM, Westerman J, Kirsten AM, et al. The 24-h lung-function profile of once-daily tiotropium and olodaterol fixed-dose combination in chronic obstructive pulmonary disease. Pulm Pharmacol Ther. 2015;32:53-9.

3. O'Donnell DE, Casaburi R, Frith P, et al. Effects of combined tiotropium/olodaterol on inspiratory capacity and exercise endurance in COPD. Eur Respir J. 2017;49(4):1601348.

4. Singh D, Ferguson GT, Bolitschek J, et al. Tiotropium + olodaterol shows clinically meaningful improvements in quality of life. Respir Med. 2015;109(10):1312-9.

5. Beeh KM, Derom E, Echave-Sustaeta J, et al. The lung function profile of once-daily tiotropium and olodaterol via Respimat ${ }^{\circledR}$ is superior to that of twice-daily salmeterol and fluticasone propionate via Accuhaler ${ }^{\circledR}$ (ENERGITO ${ }^{\circledR}$ study). Int J Chron Obstruct Pulmon Dis. 2016;11:193-205.

6. Maleki-Yazdi MR, Beck E, Hamilton AL, Korducki L, Koker P, Fogarty C. A randomised, placebo-controlled, phase II, dose-ranging trial of once-daily treatment with olodaterol, a novel long-acting beta2-agonist, for 4 weeks in patients with chronic obstructive pulmonary disease. Respir Med. 2015;109(5):596-605.
7. Hohlfeld JM, Sharma A, van Noord JA, et al. Pharmacokinetics and pharmacodynamics of tiotropium solution and tiotropium powder in chronic obstructive pulmonary disease. J Clin Pharmacol. 2014;54(4):405-14.

8. Bouyssou T, Casarosa P, Pieper M, Schnapp A, Gantner F. Synergistic bronchoprotective activity of the long-acting beta 2-agonist olodaterol with tiotropium (long-acting M3 antagonist) and ciclesonide (inhaled steroid) on the ovalbumin-induced bronchoconstriction in anaesthetized guinea pigs. Eur Respir J. 2011;38:3451.

9. Aalbers R, Maleki-Yazdi MR, Hamilton A, et al. Randomized, double-blind, dose-finding study for tiotropium when added to olodaterol, administered via the Respimat ${ }^{\circledR}$ inhaler in patients with chronic obstructive pulmonary disease. Adv Ther. 2015;32(9):809-22.

10. ClinicalTrials.gov. Efficacy and safety of 4 weeks of treatment with orally inhaled BI1744/tiotropium bromide in patients with chronic obstructive pulmonary disease (COPD). 2015. https://www. clinicaltrials.gov/ct2/show/NCT00720499. Accessed 5 Mar 2019.

11. de Miguel-Diez J, Jimenez-Garcia R. Considerations for new dual-acting bronchodilator treatments for chronic obstructive pulmonary disease. Expert Opin Investig Drugs. 2014;23(4):453-6.

12. Ferguson GT, Feldman GJ, Hofbauer P, et al. Efficacy and safety of olodaterol once daily delivered via Respimat ${ }^{\circledR}$ in patients with GOLD 2-4 COPD: results from two replicate 48 -week studies. Int J Chron Obstruct Pulmon Dis. 2014;9:629-45.

13. Koch A, Pizzichini E, Hamilton A, et al. Lung function efficacy and symptomatic benefit of olodaterol once daily delivered via Respimat ${ }^{\circledR}$ versus placebo and formoterol twice daily in patients with GOLD 2-4 COPD: results from two replicate 48-week studies. Int J Chron Obstruct Pulmon Dis. 2014;9:697-714. 